\title{
Fire-regime variability impacts forest carbon dynamics for centuries to millennia
}

\author{
Tara W. Hudiburg ${ }^{1}$, Philip E. Higuera ${ }^{2}$, and Jeffrey A. Hicke ${ }^{3}$ \\ ${ }^{1}$ Department of Forest, Rangeland, and Fire Sciences, University of Idaho, 875 Perimeter Dr., \\ Moscow, ID 83844-1133, USA \\ ${ }^{2}$ Department of Ecosystem and Conservation Sciences, University of Montana, 32 Campus Dr., \\ Missoula, MT 59812, USA \\ ${ }^{3}$ Department of Geography, University of Idaho, 875 Perimeter Dr., \\ Moscow, ID 83844-3021, USA
}

Correspondence to: Tara W. Hudiburg (thudiburg@uidaho.edu) and Philip E. Higuera (philip.higuera@umontana.edu)

Received: 11 February 2017 - Discussion started: 3 March 2017

Revised: 5 July 2017 - Accepted: 24 July 2017 - Published: 31 August 2017

\begin{abstract}
Wildfire is a dominant disturbance agent in forest ecosystems, shaping important biogeochemical processes including net carbon (C) balance. Long-term monitoring and chronosequence studies highlight a resilience of biogeochemical properties to large, stand-replacing, high-severity fire events. In contrast, the consequences of repeated fires or temporal variability in a fire regime (e.g., the characteristic timing or severity of fire) are largely unknown, yet theory suggests that such variability could strongly influence forest $\mathrm{C}$ trajectories (i.e., future states or directions) for millennia. Here we combine a 4500-year paleoecological record of fire activity with ecosystem modeling to investigate how fire-regime variability impacts soil $\mathrm{C}$ and net ecosystem carbon balance. We found that $\mathrm{C}$ trajectories in a paleo-informed scenario differed significantly from an equilibrium scenario (with a constant fire return interval), largely due to variability in the timing and severity of past fires. Paleo-informed scenarios contained multi-century periods of positive and negative net ecosystem $\mathrm{C}$ balance, with magnitudes significantly larger than observed under the equilibrium scenario. Further, this variability created legacies in soil $\mathrm{C}$ trajectories that lasted for millennia. Our results imply that fire-regime variability is a major driver of $\mathrm{C}$ trajectories in stand-replacing fire regimes. Predicting carbon balance in these systems, therefore, will depend strongly on the ability of ecosystem models to represent a realistic range of fire-regime variability over the past several centuries to millennia.
\end{abstract}

\section{Introduction}

Wildfire is a pervasive disturbance agent in forest ecosystems, strongly shaping ecosystem structure and function, including vegetation composition, nutrient cycling, and energy flow. While the immediate impacts of disturbance can be dramatic, the longevity of these impacts is less clear. In ecosystems where disturbance is historically prevalent, vegetation and biogeochemical properties typically return to predisturbance conditions over years to decades (Dunnette et al., 2014; McLauchlan et al., 2014), motivating the concept of "biogeochemical resilience" (Smithwick, 2011). Characterizing biogeochemical resilience emphasizes understanding pool sizes and changes to inputs or outputs of key elements (McLauchlan et al., 2014; Smithwick, 2011). In the context of wildfire, biogeochemical resilience is determined by pool sizes (e.g., carbon, nitrogen) prior to a fire event, elemental losses and transformations that occur during and shortly after a fire event (e.g., from volatilization and erosion), and post-fire changes in elemental pools, which in turn are determined by the rate and composition of post-fire revegetation (McLauchlan et al., 2014; Schlesinger et al., 2015; Smithwick, 2011).

Changes in the characteristic frequency or severity of fire (i.e., the fire regime) are therefore predicted to lead to compounding and potentially long-lasting changes or shifts in biogeochemical states. For example, increased disturbance frequency can deplete key growth-limiting nutrients (Yelenik et al., 2013), potentially influencing ecosystem trajec- 
tories for decades to centuries (McLauchlan et al., 2014). Net ecosystem carbon balance (NECB; the balance between net forest carbon uptake and forest losses through fire emissions; Chapin et al., 2006) is also highly sensitive to disturbance (Hudiburg et al., 2011), and while NECB trends towards 0 under a uniform disturbance regime, shifting disturbance regimes may alter NECB over centuries to millennia (Goetz et al., 2012; Kelly et al., 2016). While these ideas have a strong conceptual basis and empirical support on decadal timescales, we have lacked the data needed to test them over longer timescales - and to consider their implications for future projections - until only recently.

Coupling paleo-observations (i.e., "paleo-informed") with ecosystem modeling provides an important tool for assessing the impacts of fire-regime variability on biogeochemical dynamics by combining the mechanistic representation of ecosystem processes with actual patterns of fire activity reconstructed from the past. For example, in Alaskan boreal forests paleo-informed ecosystem modeling highlights fire as the dominant control on $\mathrm{C}$ cycling over the past millennium, far outweighing the effects of climate variability (Kelly et al., 2016). Given the significant influence of fire, estimates of modern $\mathrm{C}$ states (initial conditions for modeling future C states) can be highly sensitive to assumptions about the past fire activity. Ecosystem models typically require a spinup period to equilibrate $\mathrm{C}$ and $\mathrm{N}$ pools and can include a fixed disturbance interval (e.g., a constant fire return interval), resulting in ecosystem $\mathrm{C}$ and $\mathrm{N}$ trajectories that are in equilibrium with climate, ecosystem properties, and the disturbance regime. To initiate the model, $\mathrm{C}$ and $\mathrm{N}$ pools need to develop, as they start from bare soil with no vegetation; as vegetation grows the modeled soil pools increase, and it takes hundreds to thousands of simulation years during this spin-up period for the $\mathrm{C}$ and $\mathrm{N}$ pools to equilibrate. Following centuries of equilibrium, known disturbance events from the historical record are included, and the final results are used for initial conditions (baseline) for future scenarios. However, paleo-informed disturbance histories spanning many centuries can result in initial conditions that differ from equilibrium runs. In the boreal example, forests were a small net $\mathrm{C}$ source over the past several decades in paleo-informed simulations, whereas forests were a small net $\mathrm{C}$ sink when a constant fire return interval was assumed (Kelly et al., 2016). We would expect a similar sensitivity of $\mathrm{C}$ dynamics to fire in other stand-replacing fire regimes, although specific trajectories and impacts on modern states could vary widely, contingent on the specific history of fire activity.

Here, we pair a paleoecological record of vegetation and wildfire activity in a subalpine forest (Dunnette et al., 2014) with an ecosystem model to evaluate the sensitivity of forest ecosystem processes to fire-regime variability over a 4500year period. Our paleoecological record reveals the timing and severity of past wildfire activity within a subalpine forest watershed that was consistently dominated by lodgepole pine (Pinus contorta). We use this record to drive fire disturbances in an ecosystem model and test alternative hypotheses that help reveal the potential patterns and mechanisms causing past ecosystem change, focusing on a slowly varying carbon pool (soil C) and NECB. The resulting trends provide theoretical insight into how observed fire-regime variability can affect carbon trajectories from decadal to millennial scales. Through a series of paleo-informed and control modeling scenarios, we address two key questions about the biogeochemical impacts and legacies of wildfire activity: (1) how does centennial-to-millennial-scale variability in fire activity impact biogeochemical processes that regulate soil $\mathrm{C}$ and NECB, and (2) for how long does the legacy wildfire activity impact current biogeochemical states? In addition to testing the general hypothesis that forest carbon storage will differ between equilibrium and paleo-informed simulations, we also evaluate the impact of increasing or decreasing fire frequency, relative to that inferred from the paleo record.

\section{Materials and methods}

\subsection{Model description}

DayCent is the globally recognized daily timestep version of the biogeochemical model CENTURY, widely used to simulate the effects of climate and disturbance on ecosystem processes including forests worldwide (Bai and Houlton, 2009; Hartman et al., 2007; Savage et al., 2013). DayCent is a logical choice for our purposes, because it includes soil $\mathrm{C}$ pools that have long turnover times, spanning months to 4000 years, and thus can represent long-term ecosystem change. As used here, DayCent is aspatial, representing our ca. 30 ha study watershed as a single point. Detailed model documentation and publication lists can be found on the following website: http://www.nrel.colostate. edu/projects/daycent-downloads.html.

Required inputs for the model include vegetation cover, daily precipitation and temperature, soil texture, and disturbance histories. DayCent calculates potential plant growth as a function of water, light, and soil temperature and limits actual plant growth based on soil nutrient availability. The model includes three soil organic matter (SOM) pools (active, slow, and passive) with different decomposition rates, above and belowground litter pools, and a surface microbial pool associated with the decomposing surface litter. Plant material is split into structural and metabolic material as a function of the lignin-to-nitrogen ratio of the litter (more structural with higher lignin-to-nitrogen ratios). The active pool (microbial) has short turnover times (1-3 months), and the slow SOM pool (more resistant structural plant material) has turnover times ranging from 10 to 50 years depending on the climate. The passive pool includes physically and chemically stabilized SOM with turnover times ranging from 400 to 4000 years. For this study, DayCent was parameterized to model soil organic carbon dynamics to a depth of $30 \mathrm{~cm}$. 
Model outputs include soil $\mathrm{C}$ and $\mathrm{N}$ stocks, live and dead biomass, above- and belowground net primary productivity (NPP), heterotrophic respiration $\left(\mathrm{R}_{\mathrm{h}}\right)$, fire emissions, and net ecosystem production (NEP, defined as the difference between NPP and heterotrophic respiration). We define NECB as the difference between NEP and fire emissions.

Disturbances in DayCent are prescribed and can be parameterized to reflect severity through associated impacts to the ecosystem (e.g., biomass killed, nitrogen lost, soil eroded). The fire model in DayCent is parameterized to include the combusted and/or mortality fraction of each carbon pool (live and dead wood, foliage, coarse and fine roots, etc.) that occurs with each fire event. Erosion is also scheduled as an event in DayCent and was prescribed to occur in the same year of the observed high-severity fire events. The erosion events are thus decoupled from precipitation in the model.

\subsection{Study sites}

We studied the biogeochemical consequences of fire-regime variability by informing the DayCent model with fire history data derived from sedimentary charcoal preserved in Chickaree Lake, Colorado (Dunnette et al., 2014). Chickaree Lake $\left(40.334^{\circ} \mathrm{N}, 105.841^{\circ} \mathrm{W} ; 2796 \mathrm{~m}\right.$ above sea level) is a small, deep lake (ca. 1.5 ha surface area; $7.9 \mathrm{~m}$ depth) in a lodgepole-pine-dominated subalpine forest in Rocky Mountain National Park. The even-aged forest surrounding the lake regenerated after a high-severity (i.e., stand-replacing) fire in 1782 CE (common era) (Sibold et al., 2007). The fire regime in subalpine forests of Rocky Mountain National Park is characterized by infrequent, high-severity crown fires (ca. 100-300-year mean return intervals) associated with severe seasonal drought (Sibold et al., 2006). The mean monthly temperature is $-8.5^{\circ} \mathrm{C}$ in January and $14^{\circ} \mathrm{C}$ in July, and the average total annual precipitation is $483 \mathrm{~mm}$ (Western Regional Climate Center 1940-2013 observations from Grand Lake, CO).

Detailed methods for the collection and analysis of the Chickaree Lake sediment record are found in Dunnette et al. (2014). Briefly, the 4500-year record has an average sample resolution of 4 years and a chronology constrained by $13{ }^{210} \mathrm{~Pb}$ dates spanning the upper $20 \mathrm{~cm}$ and 25 accelerator mass spectrometry ${ }^{14} \mathrm{C}$ dates for deeper sediments. Pollen analysis indicates that the site was continuously dominated by lodgepole pine for the duration of the record presented here, with successional changes following inferred fire events (Dunnette et al., 2014). The persistence of subalpine forest over the past 4500 years is also supported by nearby pollen records in Rocky Mountain National Park (Caffrey and Doerner, 2012; Higuera et al., 2014). Dunnette et al. (2014) used macroscopic charcoal and magnetic susceptibility (a soil-erosion proxy) from Chickaree Lake to infer the timing and severity of wildfires, identifying high-severity catchment fires (those with associated erosion) and lowerseverity/extra-local fires (those without associated soil ero- sion). Thus, while all fire events were likely stand-replacing, the difference between these two fire types was the association with soil erosion. Here, we use the Chickaree Lake fire history record to inform the disturbance component of the DayCent ecosystem model by prescribing the timing and severity of past fire events within a simulated lodgepole-pinedominated subalpine forest.

\subsection{Model parameterization}

DayCent submodels associated with tree physiological parameters, site characteristics, soil parameters, and disturbance events were modified using available site-specific observations (Dunnette et al., 2014; Sibold et al., 2007), values from the literature (Kashian et al., 2013; Turner et al., 2004), and publically available climate and soil databases. Climate data required for DayCent include daily minimum and maximum temperature and precipitation, which were obtained for a 30-year period from DAYMET (Thornton, 2012). For all model runs, the 30-year climate dataset was recycled for the duration of the run; thus, climate was functionally non-varying over the duration of the simulations (beyond the variability within the 30 -year dataset). Soil texture and classification were identified using the United States National Resource Conservation Service (NRCS) SSURGO database (NRCS, 2010). Model input and parameterization files are available for download as supporting information files.

We defined two types of stand-replacing fire to distinguish between the two types of fires identified in the paleo record. The key difference between the two fire types simulated is the associated soil erosion. High-severity catchment fires from the paleo record were simulated by $95 \%$ tree mortality and a soil-erosion event with $\sim 1 \mathrm{Mg} \mathrm{ha}^{-1}$ of soil loss from the watershed (Miller et al., 2011); we refer to these as highseverity fires with erosion. Lower-severity/extra-local fires from the paleo record were simulated by $95 \%$ tree mortality with no associated soil-erosion event; we refer to these as high-severity fires without erosion. After parameterization, we evaluated modern modeled aboveground NPP, soil C, total ecosystem carbon, and disturbance $\mathrm{C}$ losses against observations of similar-aged lodgepole pine stands in the Central Rockies ecoregion (Hansen et al., 2015; Kashian et al., 2013; Turner et al., 2004).

\subsection{Model experiments}

We performed a series of modeling experiments to address our questions using the Chickaree Lake paleo-fire record, varied disturbance histories, and varied climate (Table 1). First, DayCent was spun-up and equilibrated to soil $\mathrm{C}$ and NPP levels characteristic of mature lodgepole pine stands in the region with a constant return interval of 145 years between high-severity fires with erosion, replicating the estimated fire rotation period (and mean fire return interval) for the broader study area (Sibold et al., 2007). This spin-up 
Table 1. Model simulation scenarios, including climate, fire regime, duration, and summary description.

\begin{tabular}{|c|c|c|c|c|c|}
\hline Scenario & Purpose & Climate $^{\mathrm{a}}$ & Fire regime & Duration (yr) & Description \\
\hline Spin-up & $\begin{array}{l}\text { Spin-up } \mathrm{C}, \mathrm{N} \text { pools to } \\
\text { equilibrium conditions }\end{array}$ & Ambient & $\begin{array}{l}\text { Fixed } 145 \text {-year return } \\
\text { interval; high severity } \\
\text { with erosion }\end{array}$ & 2000 & $\begin{array}{l}\text { DayCent initialization run for } \\
\text { NPP and C to reach equilibrium } \\
\text { conditions }\end{array}$ \\
\hline Equilibrium & $\begin{array}{l}\text { Run with fixed fire } \\
\text { interval }\end{array}$ & Ambient & $\begin{array}{l}\text { Fixed } 145 \text {-year return } \\
\text { interval; high severity } \\
\text { with erosion }\end{array}$ & 4561 & $\begin{array}{l}\text { Equilibrium run extended from } \\
\text { the spin-up run for the length of } \\
\text { the paleo-fire record }\end{array}$ \\
\hline Paleo-informed & $\begin{array}{l}\text { Run with observed } \\
\text { paleo-fire intervals and } \\
\text { severity }\end{array}$ & Ambient & $\begin{array}{l}\text { Paleo record; high } \\
\text { severity with } \\
\text { and without erosion }\end{array}$ & 4561 & $\begin{array}{l}\text { A 4561-year simulation with } \\
\text { fires matching the timing and } \\
\text { severity from the paleo-fire } \\
\text { record }\end{array}$ \\
\hline Increased fire frequency & $\begin{array}{l}\text { Run with paleo-fire } \\
\text { intervals decreased } \\
\text { by } 25 \%\end{array}$ & Ambient & $\begin{array}{l}\text { Modified paleo record; } \\
90 \text {-year MFRI (mean } \\
\text { fire return interval) } \\
\text { with high severity with } \\
\text { and without erosion }\end{array}$ & 4561 & $\begin{array}{l}\text { A } 4561 \text {-year simulation with } \\
\text { the timing between fires in } \\
\text { the paleo-informed scenario } \\
\text { decreased by } 25 \%\end{array}$ \\
\hline Decreased fire frequency & $\begin{array}{l}\text { Run with paleo-fire } \\
\text { intervals increased } \\
\text { by } 25 \%\end{array}$ & Ambient & $\begin{array}{l}\text { Modified paleo record; } \\
155 \text {-year MFRI with } \\
\text { high severity with and } \\
\text { without erosion }\end{array}$ & 4561 & $\begin{array}{l}\text { A } 4561 \text {-year simulation with } \\
\text { the timing between fires in } \\
\text { the paleo-informed scenario } \\
\text { increased by } 25 \%\end{array}$ \\
\hline Paleo $_{500} \ldots$ Paleo 4000 & $\begin{array}{l}\text { Test influence of length } \\
\text { of paleo record on } \\
\text { modern states }\end{array}$ & Ambient & $\begin{array}{l}\text { Paleo record; high } \\
\text { severity with and } \\
\text { without erosion }\end{array}$ & $500-4000$ & $\begin{array}{l}\text { Branches from the equilibrium } \\
\text { scenario at varying points in } \\
\text { time, in } 500 \text {-year increments. } \\
\text { all scenarios ends in } 2010 \mathrm{CE}\end{array}$ \\
\hline
\end{tabular}

a Thirty-year recycled historical record (DayMet). ${ }^{b}$ For example, the 500-year simulation starts in the year $1510 \mathrm{CE}$ and runs until the end of $2009 \mathrm{CE}$.

period lasted for 2000 years, and it represents what would be done for model use, in the absence of the long-term fire history information from the paleo record. All experimental simulations were extended from this spin-up equilibrium simulation starting 4500 years before present (BP, where present is $1950 \mathrm{CE}$ ) and running through $2010 \mathrm{CE}$, for a total of 4561 simulation years. We defined our model simulation that would normally be used in the absence of paleoinformed disturbance histories (equilibrium scenario) as a continuation of the equilibrated spin-up with the same climate and fire regime, with only the last known fire event (1782 CE) explicitly simulated.

In addition to this equilibrium scenario, we implemented three additional scenarios that together helped illustrate the duration, magnitude, and relative importance of fire-induced changes to forest biogeochemistry. First, to test the impacts of variability in fire timing and severity on important biogeochemical states, we compared the equilibrium scenario to a paleo-informed scenario, which had a mean fire return interval of 120 years for all fires and 334 years for the highseverity fires with erosion. Climate was identical in each simulation (i.e., 30-year recycled modern climate), as we are not testing the influence of climate on the timing and severity of fire, but rather the influence of the known timing and severity of fires (from the charcoal record) versus a constant fire return interval.
Second, to identify the duration of a legacy effect from fire-regime variability, we constructed eight partially paleoinformed scenarios, which included increasingly longer periods of information from the paleo-fire record, spanning the past 500 to 4000 years, in 500-year increments that ended in $2010 \mathrm{CE}$ (Paleo500, Paleo $1000, \ldots$, Paleo 4000 ; Fig. 1a). For example, the Paleo500 scenario includes the most recent 500 years of fire history, while the Paleo 4000 scenario includes the most recent 4000 years of fire history.

Thirdly, to identify how a systematic shift in fire frequency would impact carbon balance, we created two additional scenarios with shortened and lengthened fire return intervals. Beginning with the observed paleo-fire record, we modified each interval between fires to be (a) shortened by $25 \%$ (increased fire frequency) or (b) lengthened (decreased fire frequency) by $25 \%$ (Fig. 1b). The corresponding mean fire return intervals of these two additional runs were 90 years for the increased fire frequency and 155 years for the decreased fire frequency scenarios.

Because fire events in DayCent are decoupled from climate, the climate data did not impact the timing or severity of fires in the simulations. We evaluated the results from each scenario in terms of the modern end points of soil C, soil N, and NECB as well as total cumulative changes in NECB over the entire record. We define cumulative NECB as a running total, such that the sum at any given year represents the inte- 

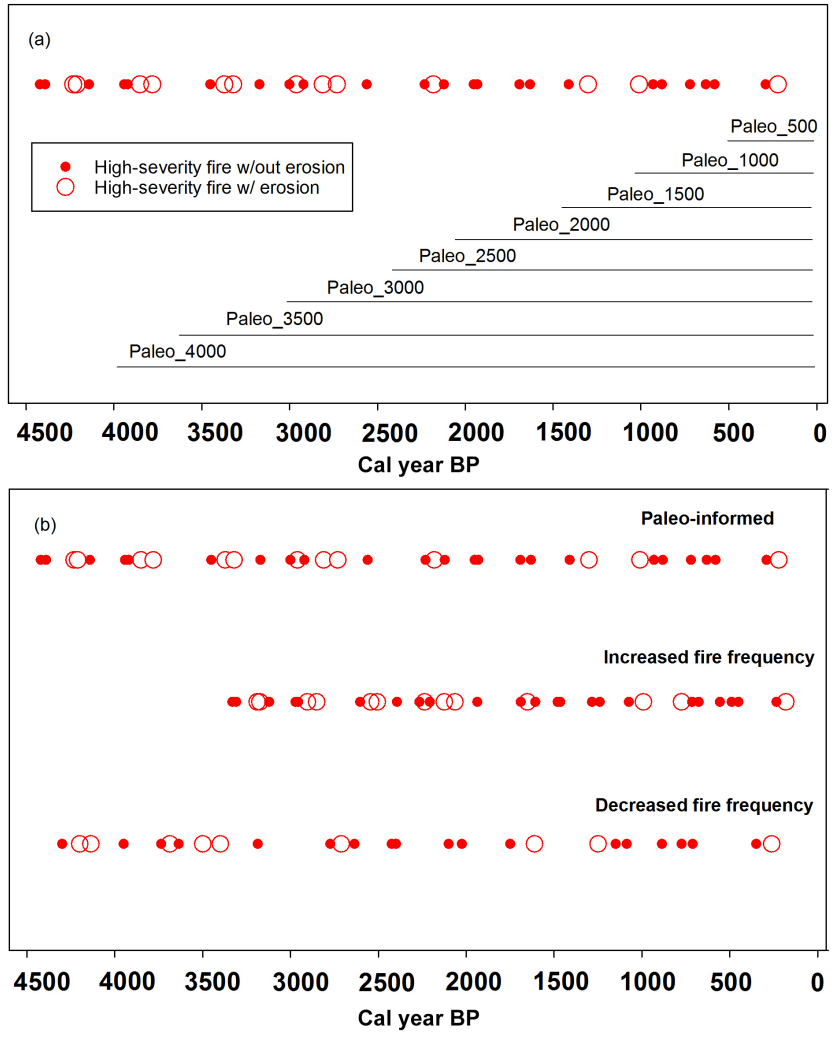

Figure 1. Paleo-informed fire history scenarios used to drive the DayCent model. (a) Fire history record form Chickaree Lake (red circles), with horizontal lines illustrating the duration of the record used in the incremental partially paleo-informed scenarios ( $\mathrm{Pa}$ leo_500...4000). (b) The same full Chickaree Lake fire history record used in the paleo-informed scenario (a), with the two additional scenarios representing a $25 \%$ increase and $25 \%$ decrease in fire frequency.

grated impacts of past disturbance events. For example, when return intervals between disturbance events are shorter than C recovery times, cumulative NECB will remain negative. Finally, we considered uncertainty in our estimates based on the uncertainty in the reconstructed fire history record, our assumptions about soil erosion, and our use of recycled modern climate. While there is also uncertainty associated with modeled estimates of soil C, NECB, and other C fluxes presented, we are not attempting to provide estimates that are any more precise than measured modern states (e.g., STATSGO-derived soil C). Rather, we compare the variability in biogeochemical states arising from fire-regime variability to the uncertainties in the model that are revealed when evaluated against modern observations from the literature.

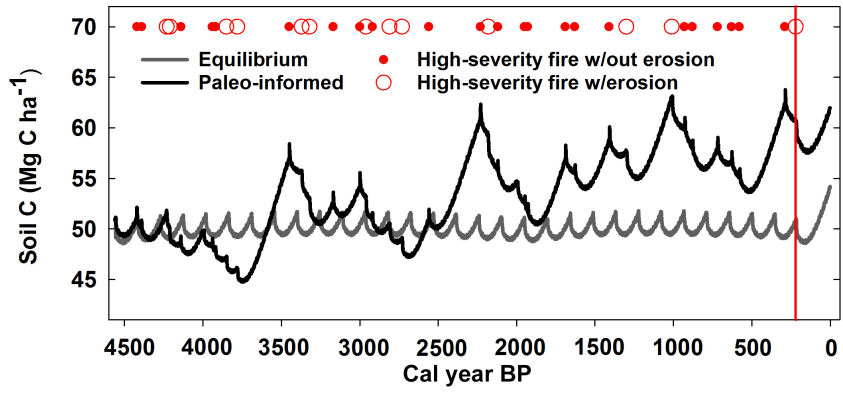

Figure 2. Model simulations of equilibrium (grey) and paleoinformed (black) total soil carbon (C) in $\mathrm{MgCha}^{-1}$. Each simulation branches from a 2000-year equilibrium spin-up starting at the same soil C baseline and runs for 4561 years (4500 BP to 2010 CE). The large open circles represent the years of the high-severity fires with erosion, and the small closed circles are high-severity fires without erosion used to drive the paleo-informed model run. A constant 145-year fire return interval was used for the equilibrium run. The vertical red line indicates the most recent stand-replacing fire $(1782 \mathrm{CE})$, reconstructed from the tree-ring record (Sibold et al., 2007).

\section{Results and discussion}

\subsection{Model parameterization and evaluation}

We compared our model results with reported values from ecological studies in the region that examined some aspect of the carbon balance in the similar-aged subalpine forests in order to evaluate our model estimates. We found few reported observations (e.g., for C, N pools, NPP) for old (>200 years) lodgepole pine stands in the Rocky Mountains in the literature. Therefore, we also compare our results with results for the same genus (Pinus) and with the soil $\mathrm{C}$ content reported by the NRCS as part of the national soil survey. Our modeled estimates of modern soil C (to $30 \mathrm{~cm}$ ) of 54 and $62 \mathrm{Mg} \mathrm{Cha}^{-1}$, for the equilibrium and paleoinformed scenario, respectively (Fig. 2), compare well with the NRCS-derived estimates (STATSGO2, NRCS, 2010) of $66 \pm 16 \mathrm{MgC} \mathrm{ha}^{-1}$ for the Chickaree Lake region and with measurements of current soil $\mathrm{C}$ (to $30 \mathrm{~cm}$ ) ranging from 51 to $73 \mathrm{Mg} \mathrm{Cha}^{-1}$ in similarly aged (> 200 years) Rocky Mountain Pinus stands (Bradford et al., 2008). Modeled estimates of aboveground NPP were also in agreement with observations, averaging 156 and $172 \mathrm{~g} \mathrm{C} \mathrm{m}^{-2}$ for the equilibrium and paleo-informed simulations, respectively, compared to estimates from the northern or central Rockies ranging from 100 to $200 \mathrm{~g} \mathrm{C} \mathrm{m}^{-2}$ (Hansen et al., 2015). Finally, fire emissions from our modeled estimates range from 20 to $30 \%$ loss of aboveground $\mathrm{C}$, broadly in agreement with other studies (Campbell et al., 2007; Smithwick et al., 2009). 


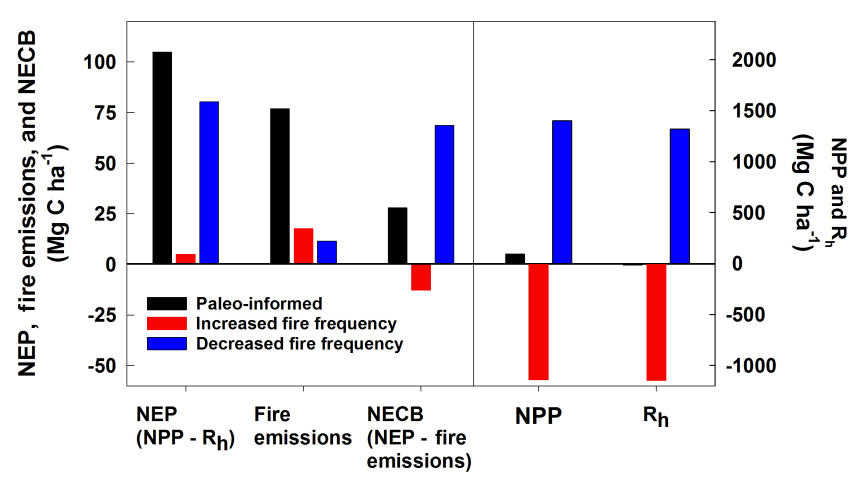

Figure 3. Accumulated anomalies in fluxes relative to the equilibrium scenario, in $\mathrm{MgCha}^{-1}$, summed over the entire 4561-year simulation period. NEP, fire emissions, and NECB (left $y$ axis) and NPP and $\mathrm{R}_{\mathrm{h}}$ (right $y$ axis) for the paleo-informed (black), increased fire frequency (red; 155-year mean FRI), and decreased fire frequency (blue; 90-year mean FRI) scenarios. Negative (positive) numbers indicate a decrease (increase) in total carbon flux compared to the equilibrium scenario.

\subsection{Fire-regime variability impacts soil C and NECB}

When DayCent was driven with the paleo-informed fire history, soil $\mathrm{C}$ accumulation was $8 \mathrm{Mg} \mathrm{ha}^{-1}$ more at the end of the simulation than in the equilibrium scenario (Fig. 2). Total NEP summed over the 4561-year period was also higher in the paleo-informed scenario $\left(1276 \mathrm{MgC} \mathrm{ha}^{-1}\right)$ compared with the equilibrium scenario $\left(1171 \mathrm{MgC} \mathrm{ha}^{-1}\right)$, directly reflecting NPP rates that were higher than heterotrophic respiration (Fig. 3, black bars). In the paleo-informed scenario, cumulative emissions due to combustion losses (i.e., fire emissions) were lower than NEP over the entire record, resulting in a cumulative NECB of $27 \mathrm{MgC} \mathrm{ha}^{-1}$ more than the equilibrium scenario (Fig. 3; black bars).

The paleo-informed scenario showed substantial variability in soil C (Fig. 2) and NECB (Fig. 4) trajectories and higher total accumulations relative to the equilibrium scenario. In fact, the range of variability in soil $\mathrm{C}$ over the paleoinformed simulation, from ca. 45 to $65 \mathrm{MgC} \mathrm{ha}^{-1}$, nearly spanned the range of observations of current soil C (to $30 \mathrm{~cm}$ ) in similarly aged ( $>200$ years) Rocky Mountain Pinus stands (Bradford et al., 2008). For the first $\sim 2000$ years of the paleo-informed scenario, long-term mean soil $\mathrm{C}$ was similar to baseline levels of soil $\mathrm{C}$ in the equilibrium scenario (Fig. 2), averaging around $54 \mathrm{MgCha}^{-1}$, though with substantial variability on centennial timescales. Following this period, the soil C trajectory increased distinctly in the paleoinformed scenario during a 500-year period with only one high-severity fire without erosion (ca. 2500 cal yr BP). Despite a return to a mean fire return interval closer to the equilibrium scenario, soil $\mathrm{C}$ persisted at this elevated level for the following 2000 years (ca. $2000 \mathrm{cal} \mathrm{yr}$ BP to present), resulting in $8 \mathrm{MgCha}^{-1}(15 \%)$ more than the equilibrium

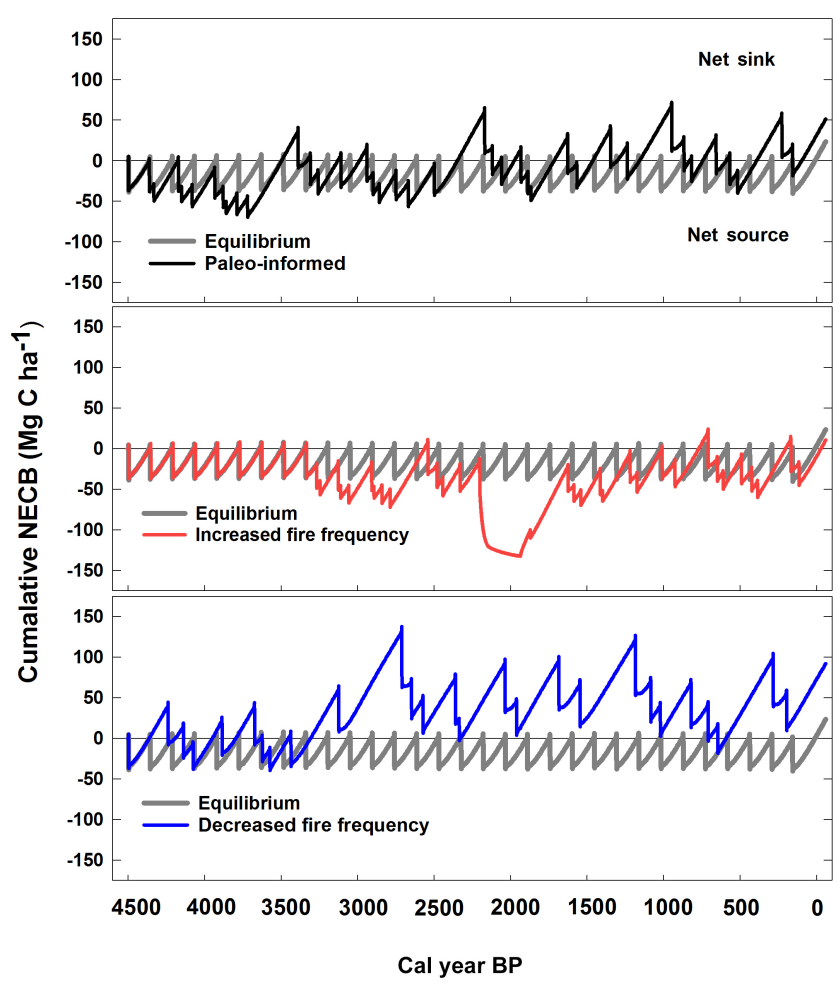

Figure 4. Trends in cumulative NECB over time for the paleoinformed, increased fire frequency, and decreased fire frequency scenarios compared to equilibrium over the last 4561 years. Positive numbers indicate a cumulative net sink, while negative numbers indicate a cumulative net source.

scenario at the end of the simulation (2010 CE). A similar trend was observed for NECB (Fig. 4), where the paleoinformed scenario maintained a lower NECB in the first half of the record compared to the second half. In the latter half of the record, NECB was more consistently positive, ultimately storing more ecosystem $\mathrm{C}$ than the equilibrium scenario. The dynamism in NECB over time is consistent with the findings of Kelly et al. (2016). Together, this work and ours highlights the value of examining the ecosystem impacts of past fire-regime variability, which may include disturbance-free or intensified disturbance periods that are not currently represented in or predicted by ecosystem models.

\subsection{Impacts of fire-regime variability last for millennia}

We compared the partially paleo-informed scenarios to the equilibrium scenario to determine the length of time necessary to arrive at the same inferences about soil $\mathrm{C}$ and NECB as in the full paleo-informed scenario. The 2010 CE end points for each partially informed scenario were compared to the $2010 \mathrm{CE}$ end point for the equilibrium scenario. We found that disturbance-regime legacies lasted for millennia. The number of years needed to simulate the 2010 CE values was between 2000 and 2500 years (Fig. 5). Specifi- 


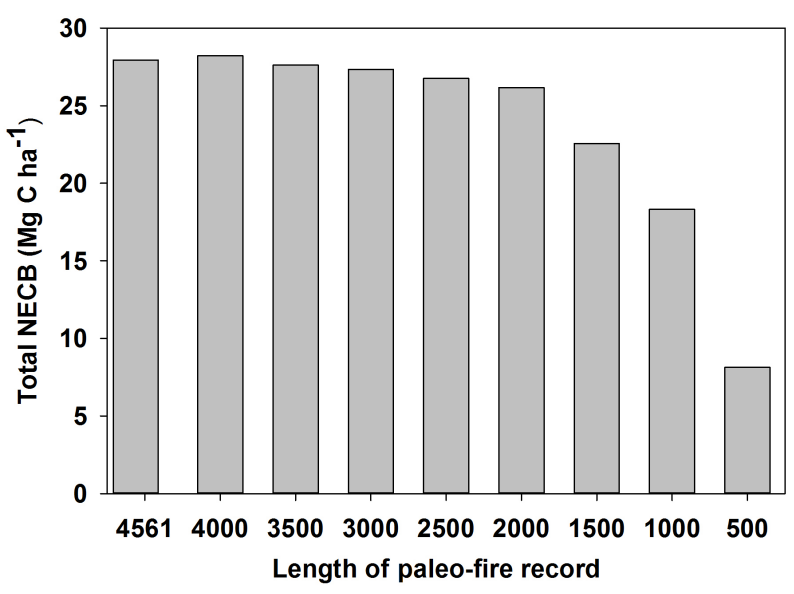

Figure 5. Total NECB (NPP $-\mathrm{R}_{\mathrm{h}}$ - fire emissions) for the 4561year simulated period and for each of the partially paleo-informed scenarios (Paleo_500, Paleo_1000, etc., in Fig. 1). Each partially paleo-informed scenario branches from the equilibrium scenario in the year indicated on the $x$ axis. For example, the 500-year record only includes fires that occurred in the most recent 500 years of the paleo-fire record (1511-2010 CE).

cally, total NECB and soil C (end points that serve as initial conditions for future modeled states) were nearly the same when using 2500 to 4500 years of the paleo-fire record but differed by more than $1 \mathrm{Mg} \mathrm{Cha}^{-1}$ when using only 500 to 2000 years of the paleo-fire record. We used the $1 \mathrm{MgCha}^{-1}$ as a significant threshold for changes in ecosystem $\mathrm{C}$ flux (total or soils) both because changes less than this indicate the ecosystem is stable and because it is a standard amount of annual $\mathrm{C}$ flux into or out of an ecosystem that is considered significant for carbon sequestration (mitigation) activities (Anderson-Teixeira et al., 2009).

Differences between the paleo-informed and equilibrium scenario can be interpreted in the context of other model parameters that are known to affect biogeochemical processes, including plant productivity and decomposition rates. Chief among these is growing season temperature, which strongly affects NPP and plant and microbial respiration in DayCent. In a simple sensitivity analysis where we repeated the equilibrium scenario with a uniform $2{ }^{\circ} \mathrm{C}$ warming during the growing season, we found that variability in the paleoinformed scenario was 1 order of magnitude greater than in the scenario with warming. Specifically, warming resulted in a small net decrease in soil $\mathrm{C}$ of $0.3 \mathrm{MgCha}^{-1}$ and a reduction in NECB by $0.2 \mathrm{MgCha}^{-1}$ relative to equilibrium scenario. Our results imply that $\mathrm{C}$ dynamics in lodgepole pine forests are far more sensitive to variability in the timing and severity of fire activity than to modeled changes to plant growth and decomposition introduced by climate warming alone. This inference is also consistent with findings from strand-replacing fire regimes in Alaskan boreal forests, where $\mathrm{C}$ dynamics over the past 1200 years were more strongly shaped by fire activity than by climate variability (Kelly et al., 2016).

\subsection{Implications for projecting future biogeochemical states}

To evaluate the effects of changing fire regimes on our results, we varied the paleo-informed disturbance regimes by increasing and decreasing the frequency of events by $25 \%$. As expected, increased fire frequency (i.e., shorter return intervals) resulted in a cumulative loss of ecosystem $\mathrm{C}$ compared to equilibrium and paleo-informed scenarios, with NECB $13 \mathrm{Mg} \mathrm{Cha}^{-1}$ lower compared to equilibrium over the entire simulation period (Fig. 3) and with periods of net carbon loss lasting nearly 800 years (Fig. 4; red line). The losses reflect large increases in fire emissions, without concurrent proportional increases in NEP (Fig. 3). In contrast, with decreased fire frequency (i.e., longer return intervals), NECB increases by $67 \mathrm{MgC} \mathrm{ha}^{-1}$ compared to equilibrium and by $40 \mathrm{Mg} \mathrm{C}^{-1}$ compared to the original paleo-informed scenario. Again, this is primarily due to an unbalanced increase in NEP compared to fire emissions (Fig. 3).

While the differences in NECB (27 Mg C more) and soil $\mathrm{C}$ ( $8 \mathrm{Mg} \mathrm{C}$ more) between the paleo-informed and equilibrium scenarios are ultimately small for this single watershed, the impact of fire-regime variability will depend on the synchrony of events on the regional and sub-continental scales (Kelly et al., 2016). This is especially important when considering the trajectory of NECB compared to equilibrium simulations during the periods of the paleo record when fire frequency or severity were higher than in the past few centuries. Cumulative NECB was negative, serving as a net source of $\mathrm{C}$ to the atmosphere, for periods of up to 500 years in the paleo-informed scenario and up to 1000 years under scenarios with increased fire frequencies.

Given the strong correspondence between observed and simulated modern $\mathrm{C}$ stocks, we have high confidence that DayCent accurately simulated the key processes shaping biogeochemical properties in our study area. Important sources of uncertainty in our estimates of past carbon dynamics stem from uncertainty in the timing and severity of past fires. The fire history reconstruction has an estimated temporal precision of several decades $( \pm 10-20$ years) (Dunnette et al., 2014), but because $C$ dynamics unfold over centuries to millennia, this level of uncertainty has negligible effects on our inferences. A more important source of uncertainty is the potential for false positives or false negatives in the fire history reconstruction: failing to detect a fire that occurred in the past or identifying a fire that did not affect the Chickaree Lake watershed. While the Chickaree Lake record clearly identified the most recent high-severity fire in the watershed (Dunnette et al., 2014), we cannot quantify accuracy over the past four millennia. However, the range of variability in individual fire return intervals reconstructed at Chickaree Lake (20-330 years) is consistent with the range of intervals recon- 
structed from other lake-sediment records in Colorado subalpine forests (Calder et al., 2015; 75-885, 45-750, 30-645, 30-1035 years, Higuera et al., 2014), suggesting that the C dynamics highlighted here are not unique to this single fire history reconstruction.

In addition to fire timing, simulated $\mathrm{C}$ dynamics were also a function of variability in fire severity, which in this study reflects the degree of soil erosion associated with standreplacing fire events. Watershed soil C losses were partially driven by the erosion events accompanying the high-severity catchment fires reconstructed in the paleo record. Because we have prescribed both fire and erosion, we cannot predict the range of soil $\mathrm{C}$ loss that may occur due to changes in precipitation regimes or if any erosion occurs with the lower-severity events; however, these results provide an estimate of expected changes in soil $\mathrm{C}$ for at least the higherseverity events. With expected changes to future precipitation regimes, including the intensification of rain events that could lead to increased erosion following fire (Larsen and MacDonald, 2007; Miller et al., 2011), ecosystem model development should include prognostic erosion to account for variability in this ecosystem process, especially on regional scales.

Finally, the most important limitation of our study is the fact that our modeling framework does not integrate realistic paleoclimate variability, nor does it represent the important coupling among climate, vegetation, and fire activity. Although paleoclimate proxies exist for nearby regions in Colorado, for example in the form of lake-level reconstructions and oxygen isotope records (Anderson 2011, 2012; Shuman et al., 2010), these records are far from the detailed climate information needed to drive DayCent. Thus, utilizing paleoclimate proxies to develop climate drivers for DayCent is an important next step but beyond the scope of this study. For example, it will involve developing methodologies to downscale paleoclimate proxies in space (to the elevation and location of Chickaree Lake), in time (to daily value), and to the specific metrics required by DayCent (e.g., from a relative moisture proxy to daily precipitation). While our simulated past carbon dynamics are limited by the lack of available paleoclimate data to drive DayCent, our temperature sensitivity analysis suggests that $\mathrm{C}$ dynamics are much more sensitive to the timing and severity of fire events than to even relatively large changes in climate (e.g., $2{ }^{\circ} \mathrm{C}$ warming). Further, because we have decoupled climate from fire by using prescribed fire events, the lack of a paleoclimate does not affect our conclusions about the impacts of fire-regime variability on $\mathrm{C}$ balance. While we used the paleo-informed modeling scenarios to test general hypotheses about the impacts of fire-regime variability on biogeochemical dynamics, future efforts to simulate the coupled climate-fire-ecosystem dynamics of the past clearly require independent paleoclimate drivers.

\section{Summary and conclusions}

Our simulations highlight fire-regime variability as a dominant driver of $\mathrm{C}$ dynamics in lodgepole pine forests, with periods of unusually high or low fire activity creating legacies lasting for centuries to millennia. Anticipating the impacts of future climate or disturbance-regime change on forest carbon balance, therefore, should be done in the context of past variability, with the duration dependent on the frequency and variability of relevant disturbance processes. In the case of stand-replacing wildfires this requires information spanning at least several centuries, and at Chickaree Lake this required several millennia, well beyond the length of both observational and tree-ring records. Many studies have reported ecosystem impacts or recovery times from individual fire events and then extrapolated to infer scenarios that would lead to C gain or loss (Dunnette et al., 2014; Kashian et al., 2013; Mack et al., 2011; Smithwick et al., 2009). In contrast, our paleo-informed scenario highlights the importance of variability in fire timing and severity over multiple fire events for carbon cycling dynamics, independent of complete shifts in a fire regime.

Our findings also have implications for ecosystem and Earth system model development, which are increasingly including prognostic fire components (Lasslop et al., 2014), primarily driven by climate and fuels. Some models are also representing post-fire $\mathrm{C}$ and $\mathrm{N}$ dynamics beyond the simple combustion of live and dead biomass or only the dead-wood pools (fuels). Development of these modules depends on observations of fire and climate interactions, fuel availability, and post-fire $\mathrm{C}$ and $\mathrm{N}$ dynamics. We suggest that this requires accurately accounting for the (often high) variability inherent in stand-replacing fire regimes, independent of or in response to climate variability. Our results indicate that even utilizing tree-ring records that span several centuries may not be sufficient to capture this variability. Further development of prognostic (predictive) fire processes in ecosystem models would benefit from the use of paleo-fire records to evaluate fire occurrence and severity, and if combined with paleoclimate data, model algorithms could be further improved to accurately reflect past variability.

The importance of fire-regime variability in determining ecosystem $\mathrm{C}$ dynamics implies that equilibrium scenarios are a poor assumption for conceptualizing and simulating fire regimes in ecosystem and Earth system models. Particularly on spatial scales larger than an individual site, such a simplification may result in C-balance projections that are grossly inaccurate. We demonstrate how variability in the timing and severity of disturbances can potentially have long-lasting and compounding impacts on biogeochemical states, such that modern (or future) states can reflect dynamics that have unfolded over centuries to millennia. For our modeling scenarios in lodgepole-pine dominated forests, the effects lasted approximately 2500 years. The duration of these legacies will depend on the ecosystem and the de- 
gree of variability in disturbance frequency and severity, relative to an equilibrium scenario. Ultimately, the implications of fire-regime variability for biogeochemical states will depend strongly on the synchrony of fire activity across spatial scales larger than a single watershed. If fire activity is synchronized on landscape to regional scales, as in the past (Calder et al., 2015; Marlon et al., 2012; Morgan et al., 2008) and as anticipated for the future (Westerling et al., 2011) in Rocky Mountain forests, we would expect to see similar centennial- to millennial-scale dynamics in biogeochemical states revealed here, which would have important implications for carbon cycling, including potential feedbacks to $\mathrm{CO}_{2}$-induced warming.

Data availability. The following datasets are available at Dryad.org (http://dx.doi.org/10.5061/dryad.74b2c): the fire history record generated from the charcoal record, the relevant model output, and model input files and the climate input file.

Author contributions. TWH and PEH designed the study, analyzed the data, and prepared the paper with contributions from JAH.

Competing interests. The authors declare that they have no conflict of interest.

Acknowledgements. We thank K. McLauchlan and B. Shuman for valuable discussions on these topics. Tara W. Hudiburg was supported by the NSF Idaho EPSCoR Program and by the National Science Foundation under award number IIA-1301792. Philip E. Higuera was supported by the National Science Foundation under award numbers IIA-0966472 and EF-1241846, and JAH was supported by the Agriculture and Food Research Initiative of the USDA National Institute of Food and Agriculture (Grant 2013-67003-20652) and the National Science Foundation under award number DMS-1520873. The authors declare no competing financial conflicts of interests or other affiliations with conflicts of interest with respect to the results of the paper.

Edited by: Kirsten Thonicke

Reviewed by: three anonymous referees

\section{References}

Anderson, L.: Holocene record of precipitation seasonality from lake calcite ${ }^{18} \mathrm{O}$ in the central Rocky Mountains, USA, Geology, 39, 211-214, 2011.

Anderson, L.: Rocky Mountain hydroclimate: Holocene variability and the role of insolation, ENSO, and the North American Monsoon, Glob. Planet. Change, 92-93, 198-208, 2012.

Anderson-Teixeira, K. J., Davis, S. C., Masters, M. D., and Delucia, E. H.: Changes in soil organic carbon under biofuel crops, Global Change Biology Bioenergy, 1, 75-96, 2009.
Bai, E. and Houlton, B. Z.: Coupled isotopic and processbased modeling of gaseous nitrogen losses from tropical rain forests, Global Biogeochem. Cy., 23, GB2011, https://doi.org/10.1029/2008gb003361, 2009.

Bradford, J. B., Birdsey, R. A., Joyce, L. A., and Ryan, M. G.: Tree age, disturbance history, and carbon stocks and fluxes in subalpine Rocky Mountain forests, Glob. Change Biol., 14, 2882 2897, https://doi.org/10.1111/j.1365-2486.2008.01686.x, 2008.

Caffrey, M. A. and Doerner, J. P.: A 7000-Year Record of Environmental Change, Bear Lake, Rocky Mountain National Park, USA, Phys. Geogr., 33, 438-456, 2012.

Calder, W. J., Parker, D., Stopka, C. J., Jiménez-Moreno, G., and Shuman, B. N.: Medieval warming initiated exceptionally large wildfire outbreaks in the Rocky Mountains, P. Natl. Acad. Sci. USA, 112, 13261-13266, 2015.

Campbell, J., Donato, D., Azuma, D., and Law, B.: Pyrogenic carbon emission from a large wildfire in Oregon, United States, J. Geophys. Res.-Biogeo., 112, G04014, https://doi.org/10.1029/2007JG000451, 2007.

Chapin, F., Woodwell, G., Randerson, J., Rastetter, E., Lovett, G., Baldocchi, D., Clark, D., Harmon, M., Schimel, D., Valentini, R., Wirth, C., Aber, J., Cole, J., Goulden, M., Harden, J., Heimann, M., Howarth, R., Matson, P., McGuire, A., Melillo, J., Mooney, H., Neff, J., Houghton, R., Pace, M., Ryan, M., Running, S., Sala, O., Schlesinger, W., and Schulze, E. D.: Reconciling carboncycle concepts, terminology, and methods, Ecosystems, 9, 10411050, 2006.

Dunnette, P. V., Higuera, P. E., McLauchlan, K. K., Derr, K. M., Briles, C. E., and Keefe, M. H.: Biogeochemical impacts of wildfires over four millennia in a Rocky Mountain subalpine watershed, New Phytol., 203, 900-912, 2014.

Goetz, S. J., Bond-Lamberty, B., Law, B. E., Hicke, J. A., Huang, C., Houghton, R. A., McNulty, S., O’Halloran, T., Harmon, M., Meddens, A. J. H., Pfeifer, E. M., Mildrexler, D., and Kasischke, E. S.: Observations and assessment of forest carbon dynamics following disturbance in North America, J. Geophys. Res.Biogeo., 117, GO2022, https://doi.org/10.1029/2011jg001733, 2012.

Hansen, E. M., Amacher, M. C., Van Miegroet, H., Long, J. N., and Ryan, M. G.: Carbon Dynamics in Central US Rockies Lodgepole Pine Type after Mountain Pine Beetle Outbreaks, Forest Sci., 61, 665-679, 2015.

Hartman, M. D., Baron, J. S., and Ojima, D. S.: Application of a coupled ecosystem-chemical equilibrium model, DayCentChem, to stream and soil chemistry in a Rocky Mountain watershed, Ecol. Model., 200, 493-510, 2007.

Higuera, P. E., Briles, C. E., and Whitlock, C.: Fire-regime complacency and sensitivity to centennial-through millennial-scale climate change in Rocky Mountain subalpine forests, Colorado, USA, J. Ecol., 102, 1429-1441, 2014.

Hudiburg, T. W., Law, B. E., Wirth, C., and Luyssaert, S.: Regional carbon dioxide implications of forest bioenergy production, Nature Climate Change, 1, 419-423, https://doi.org/10.1038/nclimate1264, 2011.

Hudiburg, T. H., Higuera, P. E., and Hicke, J. H.: Data from: Fire-regime variability impacts forest carbon dynamics for centuries to millenia, Dryad Digital Repository, https://doi.org/10.5061/dryad.74b2c, 2017. 
Kashian, D. M., Romme, W. H., Tinker, D. B., Turner, M. G., and Ryan, M. G.: Postfire changes in forest carbon storage over a 300-year chronosequence of Pinus contorta-dominated forests, Ecol. Monogr., 83, 49-66, 10.1890/11-1454.1, 2013.

Kelly, R., Genet, H., McGuire, A. D., and Hu, F. S.: Palaeodatainformed modelling of large carbon losses from recent burning of boreal forests, Nature Climate Change, 6, 79-82, 2016.

Larsen, I. J. and MacDonald, L. H.: Predicting postfire sediment yields at the hillslope scale: Testing RUSLE and Disturbed WEPP, Water Resour. Res., 43, W11412, https://doi.org/10.1029/2006WR005560, 2007.

Lasslop, G., Thonicke, K., and Kloster, S.: SPITFIRE within the MPI Earth system model: Model development and evaluation, Journal of Advances in Modeling Earth Systems, 6, 740-755, https://doi.org/10.1002/2013MS000284, 2014.

Mack, M. C., Bret-Harte, M. S., Hollingsworth, T. N., Jandt, R. R., Schuur, E. A. G., Shaver, G. R., and Verbyla, D. L.: Carbon loss from an unprecedented Arctic tundra wildfire, Nature, 475, 489492, 2011

Marlon, J. R., Bartlein, P. J., Gavin, D. G., Long, C. J., Anderson, R. S., Briles, C. E., Brown, K. J., Colombaroli, D., Hallett, D. J., and Power, M. J.: Long-term perspective on wildfires in the western USA, P. Natl. Acad. Sci. USA, 109, E535-E543, 2012.

McLauchlan, K. K., Higuera, P. E., Gavin, D. G., Perakis, S. S., Mack, M. C., Alexander, H., Battles, J., Biondi, F., Buma, B., and Colombaroli, D.: Reconstructing disturbances and their biogeochemical consequences over multiple timescales, BioScience, 64, 105-116, 2014.

Miller, M. E., MacDonald, L. H., Robichaud, P. R., and Elliot, W. J.: Predicting post-fire hillslope erosion in forest lands of the western United States, Int. J. Wildland Fire, 20, 982-999, 2011.

Morgan, P., Heyerdahl, E. K., and Gibson, C. E.: Multi-season climate synchronized forest fires throughout the 20th century, northern Rockies, USA, Ecology, 89, 717-728, 2008.

NRCS: Soil Survey Staff, Natural Resources Conservation Service, United States Department of Agriculture, available at: http:// soildatamart.nrcs.usda.gov (last access: 1 November 2016), Soil Survey Geographic (SSURGO) Database for Eastern US, 2010.

Savage, K. E., Parton, W. J., Davidson, E. A., Trumbore, S. E., and Frey, S. D.: Long-term changes in forest carbon under temperature and nitrogen amendments in a temperate northern hardwood forest, Glob. Change Biol., 19, 2389-2400, 2013.

Schlesinger, W. H., Dietze, M. C., Jackson, R. B., Phillips, R. P., Rhoades, C. C., Rustad, L. E., and Vose, J. M.: Forest biogeochemistry in response to drought, Glob. Change Biol., 22, 2318 2328, 2015.
Shuman, B., Pribyl, P., Minckley, T. A., and Shinker, J.: Rapid hydrologic shifts and prolonged droughts in Rocky Mountain headwaters during the Holocene, Geophys. Res. Lett., 37, L06701, https://doi.org/10.1029/2009GL042196, 2010.

Sibold, J. S., Veblen, T. T., and Gonzalez, M. E.: Spatial and temporal variation in historic fire regimes in subalpine forests across the Colorado Front Range in Rocky Mountain National Park, Colorado, USA, J. Biogeogr., 33, 631-647, 2006.

Sibold, J. S., Veblen, T. T., Chipko, K., Lawson, L., Mathis, E., and Scott, J.: Influences of secondary disturbances on lodgepole pine stand development in Rocky Mountain National Park, Ecol. Appl., 17, 1638-1655, 2007.

Smithwick, E. A. H., Ryan, M. G., Kashian, D. M., Romme, W. H., Tinker, D. B., and Turner, M. G.: Modeling the effects of fire and climate change on carbon and nitrogen storage in lodgepole pine (Pinus contorta) stands, Glob. Change Biol., 15, 535-548, https://doi.org/10.1111/j.1365-2486.2008.01659.x, 2009.

Smithwick, E. A. H.: Pyrogeography and biogeochemical resilience, in: The Landscape Ecology of Fire, Springer, 143-163, 2011.

Thornton, P., Thornton, M. M., Mayer, B. W., Wilhelmi, N., Wei, Y., and Cook, R. B.: Daymet: Daily surface weather on a $1 \mathrm{~km}$ grid for North America, 1980-2008, available at: http://daymet.ornl.gov/ (last access: 15 September 2016), 20 September 2012 from Oak Ridge National Laboratory Distributed Active Archive Center, O. R., Tennessee, USA, https://doi.org/10.3334/ORNLDAAC/Daymet_V2, 2012.

Turner, M. G., Tinker, D. B., Romme, W. H., Kashian, D. M., and Litton, C. M.: Landscape patterns of sapling density, leaf area, and aboveground net primary production in postfire lodgepole pine forests, Yellowstone National Park (USA), Ecosystems, 7, 751-775, 2004.

Westerling, A. L., Turner, M. G., Smithwick, E. A. H., Romme, W. H., and Ryan, M. G.: Continued warming could transform Greater Yellowstone fire regimes by mid-21st century, P. Natl. Acad. Sci. USA, 108, 13165-13170, 2011.

Yelenik, S., Perakis, S., and Hibbs, D.: Regional constraints to biological nitrogen fixation in post-fire forest communities, Ecology, 94, 739-750, 2013. 